\title{
Weight Gain Prevention for College Freshmen: Comparing Two Social Cognitive Theory-Based Interventions with and without Explicit Self-Regulation Training
}

\author{
Elizabeth A. Dennis, Kerry L. Potter, Paul A. Estabrooks, and Brenda M. Davy \\ Department of Human Nutrition, Foods and Exercise, Virginia Tech, 221 Wallace Hall (0430), Blacksburg, VA 24061, USA \\ Correspondence should be addressed to Brenda M. Davy, bdavy@vt.edu
}

Received 29 November 2011; Revised 7 March 2012; Accepted 2 April 2012

Academic Editor: Amy A. Gorin

Copyright (C) 2012 Elizabeth A. Dennis et al. This is an open access article distributed under the Creative Commons Attribution License, which permits unrestricted use, distribution, and reproduction in any medium, provided the original work is properly cited.

The college transition represents a critical period for maintaining a healthy weight, yet intervention participation and retention represent significant challenges. The objective of this investigation was to evaluate the preliminary efficacy and acceptability of two interventions to prevent freshman weight gain. One intervention provided opportunities to improve outcome expectations and self-efficacy within a social cognitive theory framework (SCT), while the other targeted the same variables but focused on explicit training in self-regulation skills (SCTSR). Methods. Freshmen $(n=45)$ aged $>18$ years were randomized to a 14 -week intervention, SCT or SCTSR; both included online modules and in-class meetings. Of the 45 students randomized, 5 withdrew before the classes began and 39 completed pre- and posttesting. Primary outcomes included body weight/composition, health behaviors, and program acceptability. Analyses included independent sample $t$-tests, repeated measures ANOVA, and bivariate correlational analyses. Results. Body weight increased over the 14-week period, but there was no group difference. Percent body fat increased in SCTSR but not SCT (mean difference: SCTSR, $+1.63 \pm 0.52 \%$; SCT, $-0.25 \pm 0.45 \% ; P=0.01$ ). Class attendance was $100 \%$ (SCTSR) and 98\% (SCT); SCTSR students (>50\%) remarked that the online tracking required "too much time." Conclusions. The intervention was well received, although there were no improvements in weight outcomes.

\section{Introduction}

It has been estimated that the average American adult gains $\sim 0.9 \mathrm{~kg}$ annually [1]. Young adults attending college demonstrate an even greater trajectory of weight gain (i.e., $1.8-$ $4.1 \mathrm{~kg}$ ) [2-5]. Importantly, weight gain, rather than initial weight status, leads to adverse changes in cardiovascular disease risk factors and the metabolic syndrome among young adults [6]. Given the large number of young adults attending college or university each year and the health implications of weight gain in this population, the early college years appear to be a critical period for promoting weight management.

Prior research in college students using qualitative interviews and focus groups indicated that, during high school, healthy meals and regular exercise were part of a student's routine, but these positive health behaviors appear to decline during the transition to college [7]. Thus, weight gain prevention efforts targeting this population should not only provide education on healthy diet and physical activity behaviors, but also instill skills in goal setting, planning, and self-monitoring, while incorporating social and environmental support to facilitate adherence and maintenance of healthy behaviors [7]. In the young adult population, low-intensity (i.e., limited or no intervention contact such as monthly phone calls or newsletters) and knowledge-only approaches that do not include recommendations for energy intake reduction do not appear to be effective in preventing weight gain [8-10]. High-intensity (i.e., frequent contact: 5 sessions/week for 16 months [11]; twice weekly for 15 weeks [12]; twice per month for two months, monthly thereafter for two years [13]) interventions that include regular group sessions or supervised exercise have been successful in producing weight maintenance in this population; however, high-intensity approaches require 
significant time for both participants and program staff, and extensive program resources. Previous interventions in this area have also focused on daily weighing without nutrition or physical activity education [14], increasing physical activity without including a dietary component (Project GRAD) [8], and short-term (6-week) social cognitive theory-based internet-based education and feedback addressing healthy eating and exercise [15]. Gow et al. [15] reported that an internet behavioral intervention combined with weight and caloric feedback was successful in maintaining body mass index (BMI) in college freshmen; however, this study was conducted over a short-time period and had overall retention rates of $68.6 \%$. Longer-term effects of the intervention on weight gain were not evaluated. Internet-based interventions promoting weight gain prevention that include social cognitive determinants have been successful in other populations such as high-school females [16] and middle-aged adults $[16,17]$. However, specific challenges that must be addressed in developing weight management interventions for the young adult population include program participation and retention [18, 19]. Formative work in this population revealed that academic course credit and monetary incentives would increase student's interest in an intervention program [7]. Previous investigations that have offered course credit as an incentive have differed in course content and intervention protocol. Matvienko et al. [10] enrolled female college freshmen into one of two groups: a nutrition science course or a control group (no course). Neither group experienced weight changes throughout the 16-month study so weight outcomes could not be attributed to the intervention alone. Sallis et al. [20] enrolled university seniors in one of two courses for credit: a physical activity intervention focusing on methods of behavioral self-management or a knowledgeoriented control course. This intervention focused primarily on physical activity measures alone without a nutritional component, and weight management outcomes were not assessed. These studies suggest that course credit offered as an incentive may increase initial participation rates within this population, but the effect on weight outcomes is unknown. While monetary incentives may improve participation rates [21] and weight management outcomes in the general adult population [22], this intervention component has not been evaluated in college-aged adults.

A number of studies described above used a social cognitive theory-based intervention that focused on promoting positive outcome expectations and self-efficacy, to varying results $[8,13,15]$. To our knowledge, an intervention targeting weight gain prevention among college freshman, which includes strategies aimed at instilling individual self-regulation (e.g., self-monitoring, goal setting, modest financial incentives as feedback), as well as physical and social environmental support for healthy lifestyle behaviors, has not been conducted. Further, these self-regulation strategies when combined with intervention content that targets outcome expectations and self-efficacy could possibly be the key to intervention success $[23,24]$. Therefore, the purpose of this investigation was to evaluate the feasibility, acceptability, and preliminary efficacy of a moderate-intensity, social cognitive theory-based intervention utilizing the internet and in-class sessions that would incorporate these selfregulation components to prevent weight gain in college freshmen and to compare this intervention approach to a social cognitive theory-based approach with a similar amount of contact, but without an explicit focus on selfregulation skills.

\section{Methods}

2.1. Subject Characteristics. Normal weight, overweight, or obese (body mass index [BMI] $18-40 \mathrm{~kg} / \mathrm{m}^{2}$ ) first-time freshmen living on campus were recruited from three dormitories on the university campus. Recruitment took place during freshman "Move-In" (i.e., the week prior to the onset of Fall semester classes). Both active and passive recruitment methods were used. Active methods included enlisting resident advisors (RAs) from each dormitory to personally invite residents to attend a group information recruitment session led by the study coordinators (ED, $\mathrm{KP})$. RAs were enlisted using email advertisements sent to dormitory supervisors, and RA recruitment incentives were used to both recruit and retain study participants. Those successful in recruiting residents who completed baseline and posttesting were compensated $\$ 10$ per resident. Passive recruitment methods included posting study fliers in dormitories and word-of-mouth.

Individuals were excluded if they were $<18$ years of age or if they reported a history of eating disorders or major chronic disease (diabetes, hypertension, heart, lung, or kidney disease). There was no upper age limit for participation, although students were required to be firsttime college freshmen who had recently graduated from high school. Students with extreme obesity (BMI $>40 \mathrm{~kg} / \mathrm{m}^{2}$ ) were ineligible due to the weight and size limit of the dualenergy X-ray absorptiometer (DXA) table and due to clinical obesity treatment guidelines which recommend substantial weight loss [25]. The study protocol was approved by the university's Institutional Review Board, and all participants provided written informed consent prior to study enrollment. Students were informed that the purpose of the study was to determine the effectiveness of two weight control programs developed for college freshmen.

\subsection{Protocol}

2.2.1. Initial Screening Procedures and Baseline Assessments. An overview of the study protocol is provided in Figure 1. Individuals meeting enrollment criteria completed baseline laboratory assessments, which included measurement of height, weight, body composition, and habitual dietary intake and physical activity level. Height was measured in centimeters without shoes using a wall-mounted stadiometer, and body weight was measured to the nearest $0.1 \mathrm{~kg}$ using a digital scale with participants wearing light clothing (shorts, t-shirt) and no shoes (Scale-Tronic model 5002, Wheaton, IL). Percentage body fat, absolute fat mass, and fat-free mass were measured using DXA (GE Lunar Prodigy; GE Healthcare, Madison, WI); this unit is able to precisely 


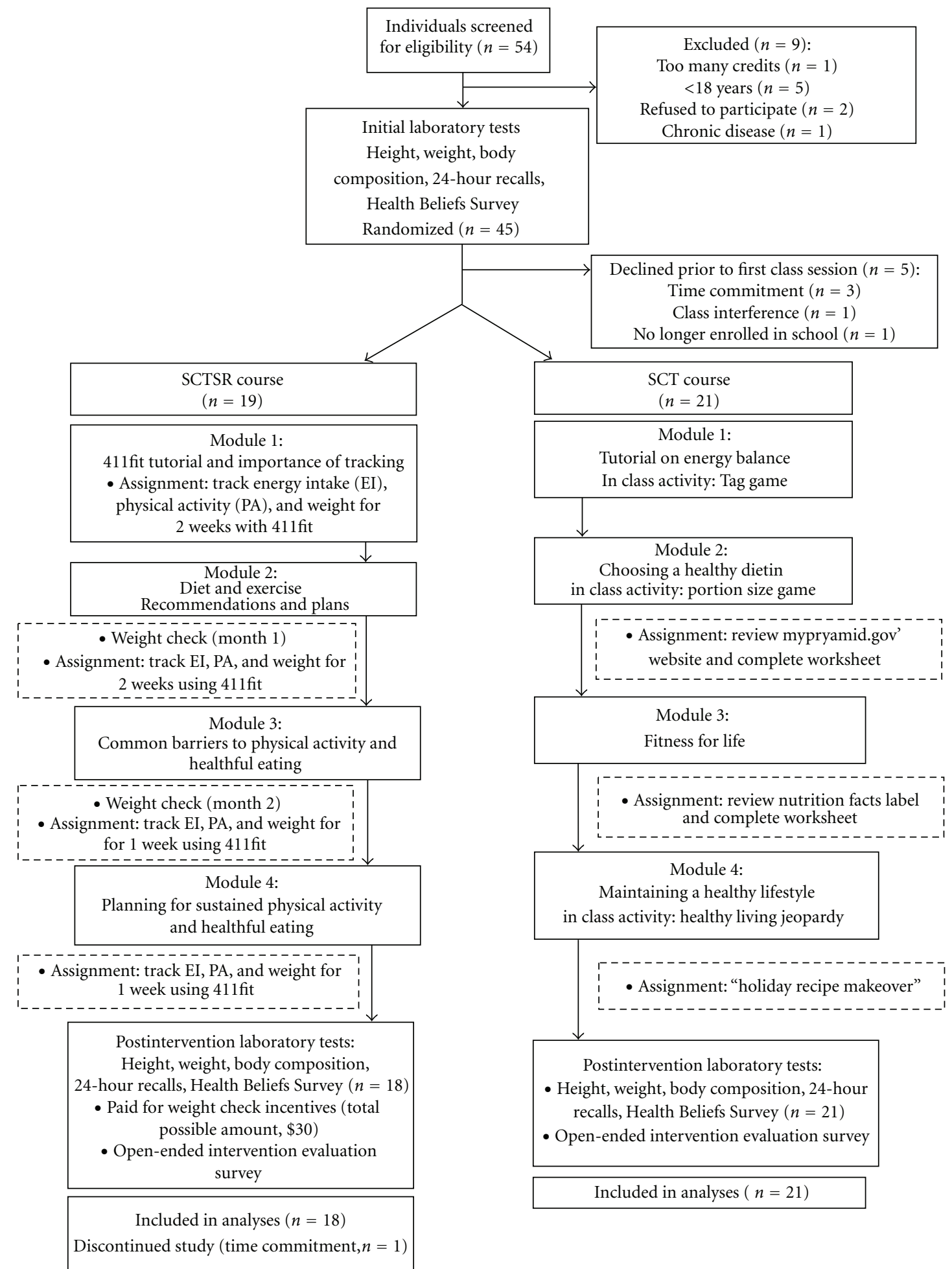

FIGURE 1: Overview: weight gain prevention in college freshmen.

determine lean body mass (root mean squared error value of $0.24 \mathrm{~kg}$ ) [26]. Habitual dietary intake was assessed using the average of three multiple pass 24-hour recalls; the multiple pass recall method is able to determine energy intake to within $8-10 \%$ of actual energy intake in both men and women $[27,28]$. The first recall was done in person at the laboratory session, and the second and third were done via telephone; recalls were collected within a two-week period by a trained research assistant. Participants were provided with two-dimensional food models to assist in portion size determination. Recalls were analyzed using dietary analysis software (NDS-R 4.05; University of Minnesota, Minneapolis, MN). Habitual physical activity was measured in minutes per week of mild, moderate, and strenuous activity, as well as 
hours per weekday/weekend day of sedentary activity using a measure that has demonstrated validity, reliability, and sensitivity to change when compared to objective measures [29]. Participants also completed a Health Beliefs Survey; this questionnaire assesses social cognitive theory determinants of diet and physical activity behaviors and has adequate to high internal consistencies (Cronbach's $\alpha=0.68-0.90$ ) [17].

2.2.2. Intervention Period. Following completion of baseline assessments, students were randomly assigned to either a social cognitive theory-based (SCT) or a social cognitive theory plus self-regulation skills training-based (SCTSR) 1credit Pass/Fail course and were enrolled during the fall semester of 2009. Of the 45 students randomized to the courses, only 2 students knew each other (they were randomly assigned to separate groups). Both courses provided an equal number of online modules and biweekly in-class sessions (50 min/session) with an instructor (M.S. or Ph.D.level graduate student in nutrition/exercise science), which lasted throughout the 14-week semester. Students in each course received equal amounts of in-person contact with the course instructor. Each module was followed by completion of a required in-class quiz. The SCT course modules (Figure 1) focused on outcome expectations by providing knowledge about healthy eating, physical activity, and their benefits; in-class sessions reinforced outcome expectations and focused self-efficacy through physical activity and nutrition lessons and experiential activities. The SCTSR course modules provided information about healthy eating and benefits of physical activity (Figure 1) but included selfregulation features. Our approach to self-regulation was based the conceptualization that it includes three general categories-self-monitoring (and the social and cognitive conditions under which one engages in self-monitoring), goal setting, and enlisting self-motivating supports and incentives to sustain health behaviors [30]. Specifically, course content and modules included information to assist students with planning and tracking, sample meal plans using foods available at university dining facilities as well as off-campus fast food restaurants, sample workout plans that could be followed at on-campus fitness facilities, and weekly emails that provided information on focused on selfregulation strategies related to diet and physical activity behaviors. For example, email content focused on selfregulatory skills related to portion control, tracking eating behaviors such as fruit/vegetable consumption, and selfmonitoring of physical activity. The SCTSR course utilized an online Internet-based tracking program entitled "411Fit" (411Fit, UNC Charlotte, Charlotte, NC) to log daily diet/activity behaviors. To receive a passing grade for the selfregulation component of the course (15\% of total grade), SCTSR students were required to complete online diet and physical activity tracking for at least $70 \%$ of total number of assigned days, as follows: two weeks in month 1, one week per month in months 2-4 (i.e., 25 of 35 assigned days). In addition to encouraging the development of planning and tracking skills, in-class sessions included content on goal setting and overcoming barriers to healthy eating and performing physical activity. During the class sessions and following each of the assignments that encouraged selfregulation skills, participants were provided with feedback on their progress and encouraged to make appropriate changes to their goals and planning strategies based on degree of successful attainment. Participants in the SCTSR course were also offered monetary incentives for maintaining their body weight (or for maintaining body fat, if weight increased due to lean mass gains) throughout the semester. This incentive was used as a reflection of self-motivating incentives based upon our preliminary qualitative work where college students indicated that financial incentives would be motivational [7]. It could also be argued that incentives align with outcome expectations and may have been an appropriate component for the SCT intervention arm. However, the alignment of incentives with goal setting and feedback (clear self-regulatory strategies) would have resulted in SCT participants explicitly setting goals thereby minimizing the difference between conditions. SCTSR participants were weighed monthly during a brief, 10-minute laboratory session (Figure 1) and offered $\$ 5, \$ 10$, and $\$ 15$ for weight maintenance at months 1,2 , and 3 , respectively, for a total of $\$ 30$ if individuals maintained weight during the entire semester and attended each monthly weigh-in. These modest incentives were intended to align with the goal of weight gain prevention as a method to provide timely feedback and encourage continued attention to the goal.

2.2.3. Posttesting. Following the intervention at the end of the semester, participants repeated baseline measurements (body weight and composition, three 24-hour food intake recalls, self-reported physical activity level, Health Beliefs Survey). All participants were compensated $\$ 20$ if they completed both pre- and posttesting measurements. Participants were also asked to disclose friends or other known acquaintances prior to starting the intervention who were in a different group to assess possible contamination, and they completed an online open-ended survey at the end of the semester to evaluate the acceptability of intervention features and overall course experience.

2.3. Statistical Analyses. Baseline group demographic characteristics were assessed using independent sample $t$-tests for continuous variables and chi-square tests for frequency variables (gender) (SPSS versus 12.0 for windows, SPSS Inc, Chicago, IL). Repeated measures ANOVA were used to assess group and time differences for subjects completing the intervention. Associations among variables were assessed by simple bivariate correlational analyses (Pearson's r). Due to the sample size and exploratory nature of the trial, we set an a priori level of significance at $P<0.10$.

\section{Results}

3.1. Baseline Characteristics. A total of 45 students were enrolled in the study, completed baseline testing, and were randomized into one of the two intervention groups. Of those, 5 students withdrew from the course prior to the 
TABLE 1: Baseline demographic characteristics of college freshmen enrolled in a 14-week weight gain prevention intervention*.

\begin{tabular}{|c|c|c|c|c|c|c|c|}
\hline & \multirow[t]{2}{*}{$\begin{array}{l}\text { Full sample } \\
\qquad(n=45)\end{array}$} & \multicolumn{3}{|c|}{$\begin{array}{l}\text { Social cognitive theory self-regulation } \\
\text { group (SCTSR; } n=24 \text { ) }\end{array}$} & \multicolumn{3}{|c|}{$\begin{array}{l}\text { Social cognitive theory } \\
\text { group (SCT; } n=21 \text { ) }\end{array}$} \\
\hline & & Male & Female & Total & Male & Female & Total \\
\hline Gender, n & $\begin{array}{c}60 \% \text { Male } \\
40 \% \text { Female }\end{array}$ & 16 & 8 & 24 & 11 & 10 & 21 \\
\hline Age, yrs & $18.1 \pm 0.1$ & $18.1 \pm 0.1$ & $18.1 \pm 0.1$ & $18.1 \pm 0.1$ & $18.2 \pm 0.2$ & $18.1 \pm 0.1$ & $18.1 \pm 0.1$ \\
\hline Height, m & $1.72 \pm 0.01$ & $1.76 \pm 0.02$ & $1.66 \pm 0.02$ & $1.73 \pm 0.02$ & $1.8 \pm 0.01$ & $1.6 \pm 0.01$ & $1.71 \pm 0.02$ \\
\hline Weight, kg & $69.5 \pm 1.9$ & $70.7 \pm 3.3$ & $70.4 \pm 6.5$ & $70.6 \pm 3.0$ & $76.8 \pm 1.4$ & $58.7 \pm 1.8$ & $68.2 \pm 2.3$ \\
\hline BMI, $\mathrm{kg} / \mathrm{m}^{2}$ & $23.4 \pm 0.6$ & $22.8 \pm 1.1$ & $25.6 \pm 2.6$ & $23.7 \pm 1.1$ & $23.9 \pm 0.4$ & $21.7 \pm 0.7$ & $22.9 \pm 0.4$ \\
\hline Body fat \% & $24.0 \pm 1.8$ & $16.0 \pm 2.8$ & $35.3 \pm 3.5$ & $22.5 \pm 2.9$ & $20.5 \pm 1.8$ & $31.7 \pm 2.9$ & $25.9 \pm 2.0$ \\
\hline Fat mass, kg & $16.8 \pm 1.5$ & $12.0 \pm 2.9$ & $23.2 \pm 4.5$ & $15.7 \pm 2.6$ & $15.1 \pm 1.4$ & $18.1 \pm 2.2$ & $16.5 \pm 1.3$ \\
\hline Fat-free mass, $\mathrm{kg}$ & $49.5 \pm 1.5$ & $55.7 \pm 1.4$ & $39.4 \pm 2.0$ & $50.3 \pm 2.0$ & $58.2 \pm 1.3$ & $37.8 \pm 1.0$ & $48.5 \pm 2.4$ \\
\hline
\end{tabular}

${ }^{*}$ Data are presented as mean \pm SEM. No baseline group differences in these variables were detected.

first class meeting causing them to be ineligible for the study. At the end of the semester, 39 students had completed the intervention and all pre- and posttesting measurements (Figure 1). Baseline sample and group demographics are shown in Table 1 . The majority of participants were white (77\%), and remaining participants were Asian or Pacific Islander $(n=4)$ and "other" $(n=6)$. Groups were not different with respect to gender $\left(\chi^{2}=0.95, d f=1, P=\right.$ $0.33)$; the only baseline group difference was in minutes/week of strenuous physical activity (Table 2) and positive physical activity outcome expectations (Table 3).

3.2. Intervention. Body composition, dietary energy intake, and physical activity variables across groups at baseline and week 14 are presented in Table 2. Weight increased in both groups, but there was no group difference in body weight over the intervention period (mean difference: SCTSR, $+1.75 \pm 0.40 \mathrm{~kg}$; SCT, $+0.95 \pm 0.43 \mathrm{~kg} ; P=0.18$ ). Percent body fat increased in the SCTSR group but not in the SCT group (mean difference: SCTSR, $+1.63 \pm 0.52 \%$; SCT, $-0.25 \pm 0.45 \% ; P=0.01$ ); however, there were no group differences over time in BMI change (SCTSR, +0.58 $\left.\pm 0.13 \mathrm{~kg} / \mathrm{m}^{2} ; \mathrm{SCT},+0.31 \pm 0.15 \mathrm{~kg} / \mathrm{m}^{2} ; P=0.18\right)$ and absolute fat mass change (SCTSR: $-0.57 \pm 1.78 \mathrm{~kg}$; SCT: $-0.01 \pm 0.40 \mathrm{~kg} ; P=0.74$ ). For the online tracking, $100 \%$ of the SCTSR participants were successful in tracking diet and physical activity behaviors at least $70 \%$ of the assigned days ( 25 of 35 assigned days). With regard to incentives for weight (or body fat) maintenance, five of the 18 SCTSR $(\sim 28 \%)$ participants received monetary incentives after the 14 -week intervention. All who received monetary incentives were male.

There were no changes over time or between groups in total dietary energy intake, macronutrients, or total dietary energy density (Table 2). Moderate and strenuous physical activity significantly declined over time; this decline was greater in the SCTSR than SCT group (Table 2). There were no changes in level of sedentary activity.

Questionnaire scores for social cognitive theory determinants of eating and physical activity behaviors are provided in Table 3. At baseline, students seldom (score of $2=$ seldom) used dietary strategies to regulate their energy and fat intake or plan/track their food intake, but following the intervention occasionally (score of $3=$ occasionally) used dietary strategies to regulate their energy and fat intake or plan/track their food intake. As expected, increases were noted in positive diet and physical activity outcome expectations, but there were no group differences. Changes in clinical laboratory measures of body composition, habitual dietary intake, and physical activity were associated (all $P<0.05)$ with changes in respective SCT determinants of eating and physical activity behaviors. Specifically, changes in positive dietary outcome expectations were correlated with changes in body fat mass $(\mathrm{kg})(r=-0.57)$. Changes in the dietary strategy of regulating energy intake and fat were correlated with changes in dietary energy intake $(r=$ $-0.50)$ and dietary energy density $(r=-0.46)$. Change in physical activity self-regulation strategies was associated with percent body fat and changes in strenuous physical activity ( $r=-0.34$ and $r=0.35$, resp.). Finally, the change in self-efficacy for overcoming barriers to physical activity was correlated with changes in strenuous physical activity and the combination of moderate and strenuous physical activity ( $r=0.41$ and $r=0.44$, resp.).

Overall class attendance for the SCTSR course and the SCT course was $100 \%$ and $98 \%$, respectively, and overall module quiz grades were $92 \%$ and $87 \%$, respectively. Course instructor evaluations (rated on a scale of $1-4 ; 1=$ poor, 4 = excellent) for each course were a mean of 3.3 and 3.7 for SCTSR and SCT courses, respectively. The results of the open-ended intervention evaluation survey, which addressed intervention acceptability, are presented in Table 4. General responses suggested that the majority of students enjoyed each course and that students would have preferred to meet more frequently throughout the semester. However, during in-class sessions, $>50 \%$ of students in the SCTSR class remarked to the instructor that the required online tracking (411fit) was excessive in terms of time required.

\section{Discussion}

Among young adults (aged 18-25 years), the college transition represents a critical period for establishing and maintaining a healthy weight [19]. Yet the challenges of 
TABLE 2: Body composition and other clinical characteristics of college freshmen before and after a 14-week weight gain prevention intervention: social cognitive theory with (SCTSR) and without (SCT) explicit self-regulation training ${ }^{\mathrm{a}}$.

\begin{tabular}{|c|c|c|c|c|c|}
\hline & \multicolumn{2}{|c|}{$\operatorname{SCTSR}(n=18)$} & \multicolumn{2}{|c|}{$\operatorname{SCT}(n=21)$} & \multirow[t]{2}{*}{$\begin{array}{c}P \text { value, time } \times \\
\text { group }\end{array}$} \\
\hline & Baseline & Week 14 & Baseline & Week 14 & \\
\hline \multicolumn{6}{|l|}{ Body weight and composition } \\
\hline Weight, $\mathrm{kg}^{\mathrm{b}}$ & $67.7 \pm 2.8$ & $69.4 \pm 2.7$ & $68.2 \pm 2.6$ & $69.1 \pm 2.5$ & 0.18 \\
\hline BMI, $\mathrm{kg} / \mathrm{m}^{2 \mathrm{~b}}$ & $22.4 \pm 1.0$ & $22.9 \pm 0.9$ & $22.9 \pm 0.4$ & $23.2 \pm 0.5$ & 0.18 \\
\hline$\%$ Body fat ${ }^{\mathrm{b}}$ & $19.1 \pm 2.5$ & $20.7 \pm 2.4$ & $25.9 \pm 2.3$ & $25.6 \pm 2.2$ & 0.01 \\
\hline Total fat mass, kg & $14.9 \pm 2.2$ & $14.4 \pm 1.9$ & $16.5 \pm 1.9$ & $16.5 \pm 1.8$ & 0.74 \\
\hline Total fat-free mass, $\mathrm{kg}^{\mathrm{b}}$ & $51.6 \pm 2.3$ & $52.0 \pm 2.4$ & $48.5 \pm 2.1$ & $49.4 \pm 2.2$ & 0.22 \\
\hline \multicolumn{6}{|l|}{ Dietary intake } \\
\hline Energy, kcal/d & $2274 \pm 203$ & $2199 \pm 213$ & $2093 \pm 188$ & $2096 \pm 198$ & 0.68 \\
\hline Carbohydrate (\% energy) & $50.5 \pm 1.7$ & $50.9 \pm 1.6$ & $50.9 \pm 1.5$ & $49.7 \pm 1.5$ & 0.56 \\
\hline Protein (\% energy) & $14.3 \pm 0.7$ & $15.1 \pm 0.9$ & $15.7 \pm 0.7$ & $16.1 \pm 0.8$ & 0.74 \\
\hline Fat (\% energy) & $34.5 \pm 1.5$ & $34.1 \pm 1.3$ & $33.8 \pm 1.3$ & $34.2 \pm 1.2$ & 0.73 \\
\hline Energy density, $\mathrm{kcal} / \mathrm{g}^{\mathrm{c}}$ & $0.76 \pm 0.05$ & $0.87 \pm 0.05$ & $0.75 \pm 0.05$ & $0.82 \pm 0.05$ & 0.43 \\
\hline \multicolumn{6}{|l|}{ Physical activity } \\
\hline Mild physical activity, min/wk & $224 \pm 52$ & $264 \pm 44$ & $198 \pm 48$ & $157 \pm 41$ & 0.40 \\
\hline Moderate physical activity, min/wk ${ }^{\mathrm{b}}$ & $244 \pm 55$ & $83 \pm 15$ & $123 \pm 51$ & $92 \pm 14$ & 0.10 \\
\hline Strenuous physical activity, min/wk ${ }^{\mathrm{bd}}$ & $338 \pm 66$ & $142 \pm 35$ & $160 \pm 59$ & $175 \pm 31$ & 0.007 \\
\hline Strength training physical activity, min/wk & $93 \pm 24$ & $72 \pm 24$ & $86 \pm 22$ & $91 \pm 22$ & 0.40 \\
\hline Weekday sedentary activity, hours/day & $8.2 \pm 1.1$ & $7.5 \pm 0.7$ & $6.6 \pm 1.1$ & $7.2 \pm 0.7$ & 0.53 \\
\hline Weekend sedentary activity, hours/day & $5.8 \pm 0.9$ & $6.7 \pm 0.6$ & $5.8 \pm 0.8$ & $6.9 \pm 0.6$ & 0.83 \\
\hline
\end{tabular}

recruiting young adults to participate in weight management interventions and in retention rates have been recognized $[18,19]$. The purpose of this investigation was to evaluate the feasibility, acceptability, and preliminary efficacy of two moderate-intensity interventions created to prevent weight gain in college freshmen. An additional purpose was to compare this SCTSR intervention to an SCT program that lacked an explicit focus on self-regulation skills. Although recruitment and retention did not represent significant problems in this investigation, the intervention was unsuccessful in preventing weight gain over the 14-week period. Previous studies have demonstrated yearly average weight gains of 1.8$4.1 \mathrm{~kg}[2-4,31]$, and if students in this investigation continued to gain weight at the same rate, they would be within that range by the end of their first year in college. Although there was no group difference in weight gain over the 14week period, the SCT intervention group maintained relative (i.e., \%) and absolute fat mass as compared to the SCTSR group. Students enrolled in the SCTSR course expressed to instructors that they believed the course required more time and effort than would be expected for a one-credit course, which may have contributed to the lack of positive weightrelated outcomes. Consistent with this possibility, one student in the SCTSR course discontinued the study because of the time commitment required. In contrast, the students in the SCT course reported that they associated the class with "having fun" and requested items such as daily meal plans to help them reach their goals. In addition, the openended survey results suggested that students would have benefited from additional in-class sessions. This intervention did not include pre- and postintervention nutrition and physical activity knowledge tests. Instead, biweekly quizzes were utilized to evaluate compliance with completing online class modules. As this was part of a for-credit course, students may have focused more on completing course requirements and tracking/homework assignments instead of utilizing the weight gain prevention skills for their own benefit and health.

Overall, both approaches appeared acceptable in that both groups had high class attendance and quiz grades, favorable course and instructor ratings, and very low attrition (i.e., one dropout). Indeed, relative to retention in other similar studies, both SCTSR and SCT were very high $[13,15]$. It is unclear whether these high retention rates may be attributed to the incentive of course credit. Students were informed of university policies related to maintaining full-time status prior to enrollment to allow students the opportunity to discontinue the study if they decided to withdraw from the course. If so, this may have limited the initial enrollment numbers. On the other hand, five students were enrolled in the course but discontinued the study prior to the first class session, and subsequent retention rates were high. Previous studies utilizing the incentive of academic credit report varying retention rates. Matvienko et al. reported higher retention rates for the duration of the course but failed to 
TABLE 3: Social cognitive determinants of eating and physical activity behaviors in college freshmen before and after a 14-week weight gain prevention study: social cognitive theory with (SCTSR) and without (SCT) explicit self-regulation training ${ }^{\mathrm{a}}$.

\begin{tabular}{|c|c|c|c|c|c|}
\hline & \multicolumn{2}{|c|}{$\operatorname{SCTSR}(n=18)$} & \multicolumn{2}{|c|}{$\operatorname{SCT}(n=21)$} & \multirow{2}{*}{$\begin{array}{c}P \text { value, time } \\
\text { group }\end{array}$} \\
\hline & Baseline & Week 14 & Baseline & Week 14 & \\
\hline \multicolumn{6}{|l|}{ Dietary strategies } \\
\hline Regulating energy and fat ${ }^{\mathrm{b}}$ & $2.2 \pm 0.2$ & $2.9 \pm 0.2$ & $2.6 \pm 0.2$ & $3.2 \pm 0.2$ & 0.67 \\
\hline Planning and tracking ${ }^{\mathrm{b}}$ & $2.3 \pm 0.2$ & $2.9 \pm 0.2$ & $2.5 \pm 0.2$ & $3.1 \pm 0.2$ & 0.89 \\
\hline Regulating fruit and vegetables & $3.6 \pm 0.2$ & $3.7 \pm 0.2$ & $3.7 \pm 0.2$ & $3.9 \pm 0.1$ & 0.85 \\
\hline \multicolumn{6}{|l|}{ Dietary Self-regulatory efficacy } \\
\hline Keeping track & $73.6 \pm 4.9$ & $71.0 \pm 5.0$ & $71.9 \pm 4.5$ & $72.1 \pm 4.7$ & 0.60 \\
\hline Fruit and vegetables & $66.4 \pm 4.4$ & $66.1 \pm 5.0$ & $72.0 \pm 4.0$ & $74.7 \pm 4.7$ & 0.56 \\
\hline \multicolumn{6}{|l|}{ Dietary outcome expectations } \\
\hline Positive $^{\mathrm{b}}$ & $3.9 \pm 0.1$ & $4.4 \pm 0.2$ & $4.3 \pm 0.1$ & $4.6 \pm 0.1$ & 0.65 \\
\hline Negative & $2.4 \pm 0.2$ & $2.5 \pm 0.2$ & $2.6 \pm 0.2$ & $2.6 \pm 0.2$ & 0.37 \\
\hline \multicolumn{6}{|l|}{ Physical activity (PA) } \\
\hline Self-regulation & $3.2 \pm 0.2$ & $3.2 \pm 0.2$ & $3.3 \pm 0.2$ & $3.6 \pm 0.2$ & 0.42 \\
\hline Self-efficacy to integrate PA into daily routine & $73.3 \pm 4.1$ & $75.0 \pm 3.8$ & $78.7 \pm 3.8$ & $80.7 \pm 3.5$ & 0.96 \\
\hline PA barriers self efficacy & $59.8 \pm 5.1$ & $60.2 \pm 4.5$ & $67.9 \pm 4.7$ & $73.4 \pm 4.2$ & 0.43 \\
\hline \multicolumn{6}{|l|}{ PA outcome expectations } \\
\hline Positive $^{b c}$ & $4.0 \pm 0.1$ & $4.1 \pm 0.1$ & $4.3 \pm 0.1$ & $4.5 \pm 0.1$ & 0.32 \\
\hline Negative & $2.2 \pm 0.1$ & $2.2 \pm 0.1$ & $2.1 \pm 0.1$ & $2.0 \pm 0.1$ & 0.81 \\
\hline
\end{tabular}

${ }^{a}$ Data are presented as mean \pm SEM.

${ }^{b}$ Main effect of time, $P<0.10$.

${ }^{\mathrm{c}}$ Group difference at baseline, $P<0.10$.

retain subjects for follow-up testing [10], whereas Sallis et al. experienced a 53\% and 25\% dropout rate in the first and second semesters, respectively [20].

Identifying effective weight management intervention approaches for this population continues to be a challenge. Short-term interventions (six-16 weeks) aimed at preventing weight gain in young adults have reported positive outcomes using both small- and large-change self-regulation interventions [32] and a theory-based online intervention combined with email feedback [15]. Retention rates were relatively high $(\sim 80 \%)$ in the combined intervention group of the latter investigation [15], although the study duration was relatively brief (i.e., six weeks). One longer-duration educational/behavioral intervention study which utilized small-group seminars for first- and second-year college students reported favorable outcomes; compared to the control condition, body weight in the intervention group was $1.3 \mathrm{~kg}$ lower after two years [13]. Study retention rate in this investigation was $83 \%$; however, the study population consisted of health science majors, who may not be representative of the general college student population.

Prior work in college students indicated that both monetary incentives and academic course credit would increase student's interest in participating in a program aimed at improving weight-related health behaviors [7]. As a component of interventions aimed at improving health behaviors, monetary incentives appear to have beneficial effects on weight management outcomes in the general adult population over a six- to 18-month-time period [22].
However, the effectiveness of incentives to improve weight management outcomes within special populations groups, such as economically disadvantaged individuals or collegeaged adults, is not known. The findings of this investigation do not suggest that a moderate intensity SCTSR intervention which includes monetary and academic (i.e., course credit) incentives will prevent weight gain among college freshmen.

Although our interventions were unsuccessful in preventing weight gain, there are several strengths that should be noted. Measures of both weight and body composition (DXA) were included, as opposed to weight alone or BMI. In young adult males, body composition may be a more appropriate outcome variable than body weight alone as growth may still be taking place; the DXA assesses fat mass and fat-free mass, both of which may contribute to body weight gain. The increase in fat-free mass over time (Table 2) provides support for this point. Inclusion of the open-ended intervention course survey provided valuable (and largely positive) feedback, attendance was high and attrition was minimal in both intervention courses, knowledge gains were demonstrated as suggested by the high quiz grades, and instructor ratings were in the "good" to "excellent" range. A final strength is that the course format was designed and delivered in a way that could be duplicated and disseminated to other universities, through the use of online components/modules and structured in-class sessions.

This study is limited by a small sample size and short study duration. Thus, we are unable to extrapolate the findings beyond our sample or to address the degree to which body composition changes were sustained over a 
TABLe 4: Open-ended exit survey results. Program acceptability and perceptions of social cognitive theory with (SCTSR) and without (SCT) explicit self-regulation training targeting weight gain prevention*.

\begin{tabular}{|c|c|c|}
\hline & $\operatorname{SCTSR}(n=18)$ & $\operatorname{SCT}(n=21)$ \\
\hline \multicolumn{3}{|l|}{$\begin{array}{l}\text { How did this class help you focus on healthy } \\
\text { eating and physical activity? }\end{array}$} \\
\hline & Increased awareness of daily food intake (4) & $\begin{array}{l}\text { Increased awareness of healthy } \\
\text { campus options and food intake (9) }\end{array}$ \\
\hline & Helped with daily food intake choices (2) & $\begin{array}{l}\text { Improved my physical activity and } \\
\text { healthy eating behaviors (4) }\end{array}$ \\
\hline & It obsessed over it (1) & $\begin{array}{l}\text { I learned different activities for } \\
\text { exercise (1) }\end{array}$ \\
\hline & Made me realize eating healthy is not that hard (1) & \\
\hline \multicolumn{3}{|l|}{$\begin{array}{l}\text { How would you change the class to make it } \\
\text { more meaningful for future freshmen? }\end{array}$} \\
\hline & Make the class sessions more interactive (1) & $\begin{array}{l}\text { Increase number of class sessions } \\
\text { throughout the semester }(4)\end{array}$ \\
\hline & $\begin{array}{l}\text { Increase number of class sessions throughout the } \\
\text { semester (1) }\end{array}$ & $\begin{array}{l}\text { Include tracking behaviors or } \\
\text { sample meal plans and workouts (3) }\end{array}$ \\
\hline & $\begin{array}{l}\text { Include more detail and emphasis on adverse } \\
\text { health risks of obesity and physical inactivity (1) }\end{array}$ & $\begin{array}{l}\text { Make the class sessions more } \\
\text { interactive to engage students ( } 3 \text { ) }\end{array}$ \\
\hline & $\begin{array}{l}\text { "Teach people to slowly incorporate more and } \\
\text { more healthy habits that fit into their schedule. } \\
\text { Do not make drastic changes. Do not fill up on } \\
\text { high volume, low calorie foods or fake sweeteners } \\
\text { like this class tells you to. They fake-out your } \\
\text { body and your body will not like it" (1) }\end{array}$ & Class is adequate the way it is ( 3 ) \\
\hline & $\begin{array}{l}\text { Make logging physical activity part of } \\
\text { participation (1) }\end{array}$ & Increase physical activity (1) \\
\hline \multicolumn{3}{|l|}{ Please provide any other general comments: } \\
\hline & Fun class/enjoyed experience (2) & Great class/enjoyed experience (5) \\
\hline & Teaches unhealthy/over obsessive eating habits (1) & Liked the class and instructors (2) \\
\hline & Tracking weight gain was interesting (1) & \\
\hline & Keep the class organized (1) & \\
\hline
\end{tabular}

\footnotetext{
* Number of similar comments indicated in parentheses.
}

longer period of time. However, the randomization procedure, use of objective measures of body composition, and assessing changes of potential intervention mediators are improvements over previous studies examining weight gain prevention in this population. The latter feature is especially important in that we identified consistent and expected relationships between the changes in social cognitive theory variables and changes in behavioral and weight status outcomes. This suggests that, while the SCTSR and SCT may not have been successful in universal weight gain prevention, the targeted variables are viable for consideration in developing future interventions for this target population.

\section{Conclusions}

To our knowledge, this is first weight gain prevention intervention trial for college freshman, which includes strategies aimed at instilling individual behavior change skills (e.g., self-regulation, self-monitoring, goal setting, financial incentives), as well as physical and social environmental support for healthy lifestyle behaviors. The intervention programs appeared to be well received and feasible to deliver, although knowledge gains did not lead to improvements in weight-related outcomes. Future studies should address program components such as self-regulation strategies and incentives which are effective for this population, while addressing issues related to student's perceived time constraints, program feasibility, and dissemination potential.

\section{Acknowledgments}

This work was funded by NIH K01 DK075424 and the Virginia Tech Fralin Life Science Institute.

\section{References}

[1] J. O. Hill, H. R. Wyatt, G. W. Reed, and J. C. Peters, "Obesity and the environment: where do we go from here?" Science, vol. 299, no. 5608, pp. 853-855, 2003.

[2] D. A. Anderson, J. R. Shapiro, and J. D. Lundgren, "The freshman year of college as a critical period for weight 
gain: an initial evaluation," Eating Behaviors, vol. 4, no. 4, pp. 363-367, 2003.

[3] D. A. Levitsky, C. A. Halbmaier, and G. Mrdjenovic, "The freshman weight gain: a model for the study of the epidemic of obesity," International Journal of Obesity, vol. 28, no. 11, pp. 1435-1442, 2004.

[4] S. B. Racette, S. S. Deusinger, M. J. Strube, G. R. Highstein, and R. H. Deusinger, "Weight changes, exercise, and dietary patterns during freshman and sophomore years of college," Journal of American College Health, vol. 53, no. 6, pp. 245-251, 2005.

[5] E. E. Lloyd-Richardson, S. Bailey, J. L. Fava, and R. Wing, "A prospective study of weight gain during the college freshman and sophomore years," Preventive Medicine, vol. 48, no. 3, pp. 256-261, 2009.

[6] D. M. Lloyd-Jones, A. R. Dyer, R. Wang, M. L. Daviglus, and P. Greenland, "Risk factor burden in middle age and lifetime risks for cardiovascular and non-cardiovascular death (Chicago Heart Association Detection Project in Industry)," American Journal of Cardiology, vol. 99, no. 4, pp. 535-540, 2007.

[7] K. A. Strong, S. L. Parks, E. Anderson, R. Winett, and B. M. Davy, "Weight gain prevention: identifying theory-based targets for health behavior change in young adults," Journal of the American Dietetic Association, vol. 108, no. 10, pp. 1708$1715,2008$.

[8] K. J. Calfas, J. F. Sallis, J. F. Nichols et al., "Project GRAD: two-year outcomes of a randomized controlled physical activity intervention among young adults," American Journal of Preventive Medicine, vol. 18, no. 1, pp. 28-37, 2000.

[9] R. W. Jeffery and S. A. French, "Preventing weight gain in adults: the pound of prevention study," American Journal of Public Health, vol. 89, no. 5, pp. 747-751, 1999.

[10] O. Matvienko, D. S. Lewis, and E. Schafer, "A college nutrition science course as an intervention to prevent weight gain in female college freshmen," Journal of Nutrition Education and Behavior, vol. 33, no. 2, pp. 95-101, 2001.

[11] J. E. Donnelly, J. O. Hill, D. J. Jacobsen et al., "Effects of a 16month randomized controlled exercise trial on body weight and composition in young, overweight men and women: the midwest exercise trial," Archives of Internal Medicine, vol. 163, no. 11, pp. 1343-1350, 2003.

[12] E. Stice, K. Orjada, and J. Tristan, “Trial of a psychoeducational eating disturbance intervention for college women: a replication and extension," International Journal of Eating Disorders, vol. 39, no. 3, pp. 233-239, 2006.

[13] M. F. Hivert, M. F. Langlois, P. Bérard, J. P. Cuerrier, and A. C. Carpentier, "Prevention of weight gain in young adults through a seminar-based intervention program," International Journal of Obesity, vol. 31, no. 8, pp. 1262-1269, 2007.

[14] D. A. Levitsky, J. Garay, M. Nausbaum, L. Neighbors, and D. M. DellaValle, "Monitoring weight daily blocks the freshman weight gain: a model for combating the epidemic of obesity," International Journal of Obesity, vol. 30, no. 6, pp. 1003-1010, 2006.

[15] R. W. Gow, S. E. Trace, and S. E. Mazzeo, "Preventing weight gain in first year college students: an online intervention to prevent the "freshman fifteen'"' Eating Behaviors, vol. 11, no. 1, pp. 33-39, 2010.

[16] R. A. Winett, D. F. Tate, E. S. Anderson, J. R. Wojcik, and S. G. Winett, "Long-term weight gain prevention: a theoretically based Internet approach," Preventive Medicine, vol. 41, no. 2, pp. 629-641, 2005.

[17] R. A. Winett, E. S. Anderson, J. R. Wojcik, S. G. Winett, and T. Bowden, "Guide to health: nutrition and physical activity outcomes of a group-randomized trial of an internet-based intervention in churches," Annals of Behavioral Medicine, vol. 33, no. 3, pp. 251-261, 2007.

[18] J. Gokee-Larose, A. A. Gorin, H. A. Raynor et al., "Are standard behavioral weight loss programs effective for young adults?" International Journal of Obesity, vol. 33, no. 12, pp. 1374-1380, 2009.

[19] A. S. Poobalan, L. S. Aucott, E. Precious, I. K. Crombie, and W. C. S. Smith, "Weight loss interventions in young people (18 to 25 year olds): a systematic review," Obesity Reviews, vol. 11, no. 8, pp. 580-592, 2010.

[20] J. F. Sallis, K. J. Calfas, J. E. Alcaraz, C. Gehrman, and M. F. Johnson, "Potential mediators of change in a physical activity promotion course for university students: project grad," Annals of Behavioral Medicine, vol. 21, no. 2, pp. 149$158,1999$.

[21] D. J. Hennrikus and R. W. Jeffery, "Worksite intervention for weight control: a review of the literature," American Journal of Health Promotion, vol. 10, no. 6, pp. 471-498, 1996.

[22] J. Wall, C. Ni Mhurchu, T. Blakely, A. Rodgers, and J. Wilton, "Effectiveness of monetary incentives in modifying dietary behavior: a review of randomized, controlled trials," Nutrition Reviews, vol. 64, no. 12, pp. 518-531, 2006.

[23] E. S. Anderson, R. A. Winett, and J. R. Wojcik, "Selfregulation, self-efficacy, outcome expectations, and social support: social cognitive theory and nutrition behavior," Annals of Behavioral Medicine, vol. 34, no. 3, pp. 304-312, 2007.

[24] E. S. Anderson, R. A. Winett, J. R. Wojcik, and D. M. Williams, "Social cognitive mediators of change in a group randomized nutrition and physical activity intervention: social support, self-efficacy, outcome expectations and self-regulation in the guide-to-health trial," Journal of Health Psychology, vol. 15, no. 1, pp. 21-32, 2010.

[25] "Clinical Guidelines on the Identification, Evaluation, and Treatment of Overweight and Obesity in Adults," The Evidence Report. NIH Publication No. 98-4083, National Institutes of Health, 1998.

[26] K. Hind, B. Oldroyd, and J. G. Truscott, "In vivo precision of the GE Lunar iDXA densitometer for the measurement of total body composition and fat distribution in adults," European Journal of Clinical Nutrition, vol. 65, no. 1, pp. 140-142, 2011.

[27] J. M. Conway, L. A. Ingwersen, and A. J. Moshfegh, "Accuracy of dietary recall using the USDA five-step multiple-pass method in men: an observational validation study," Journal of the American Dietetic Association, vol. 104, no. 4, pp. 595-603, 2004.

[28] J. M. Conway, L. A. Ingwersen, B. T. Vinyard, and A. J. Moshfegh, "Effectiveness of the US Department of Agriculture 5 -step multiple-pass method in assessing food intake in obese and nonobese women," American Journal of Clinical Nutrition, vol. 77, no. 5, pp. 1171-1178, 2003.

[29] G. Godin and R. J. Shephard, "A simple method to assess exercise behavior in the community," Canadian Journal of Applied Sport Sciences, vol. 10, no. 3, pp. 141-146, 1985.

[30] A. Bandura, "The primacy of self-regulation in health promotion," Applied Psychology, vol. 54, no. 2, pp. 245-254, 2005.

[31] D. M. Lloyd-Jones, K. Liu, L. A. Colangelo et al., "Consistently stable or decreased body mass index in young adulthood 
and longitudinal changes in metabolic syndrome components: the coronary artery risk development in young adults study," Circulation, vol. 115, no. 8, pp. 1004-1011, 2007.

[32] J. Gokee LaRose, D. F. Tate, A. A. Gorin, and R. R. Wing, "Preventing weight gain in young adults: a randomized controlled pilot study," American Journal of Preventive Medicine, vol. 39, no. 1, pp. 63-68, 2010. 


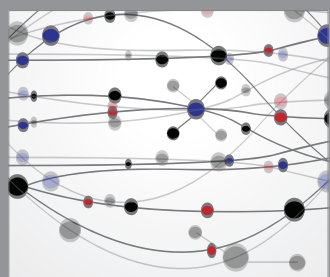

The Scientific World Journal
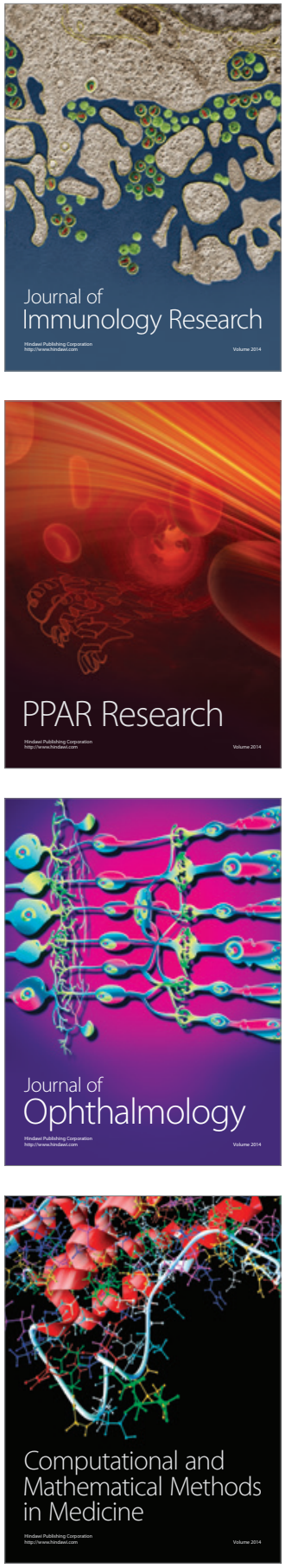

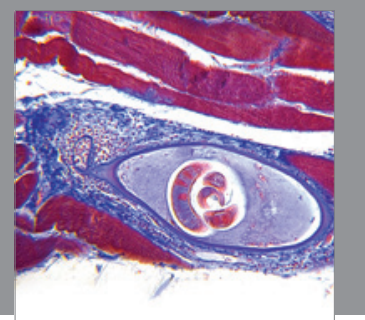

Gastroenterology

Research and Practice
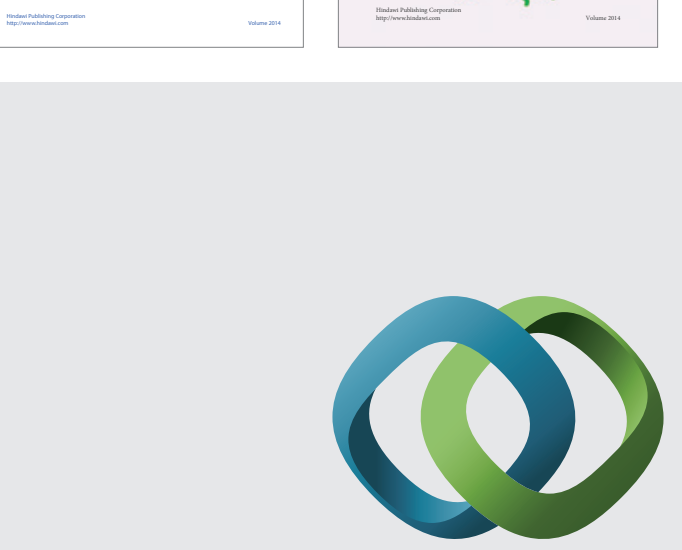

\section{Hindawi}

Submit your manuscripts at

http://www.hindawi.com
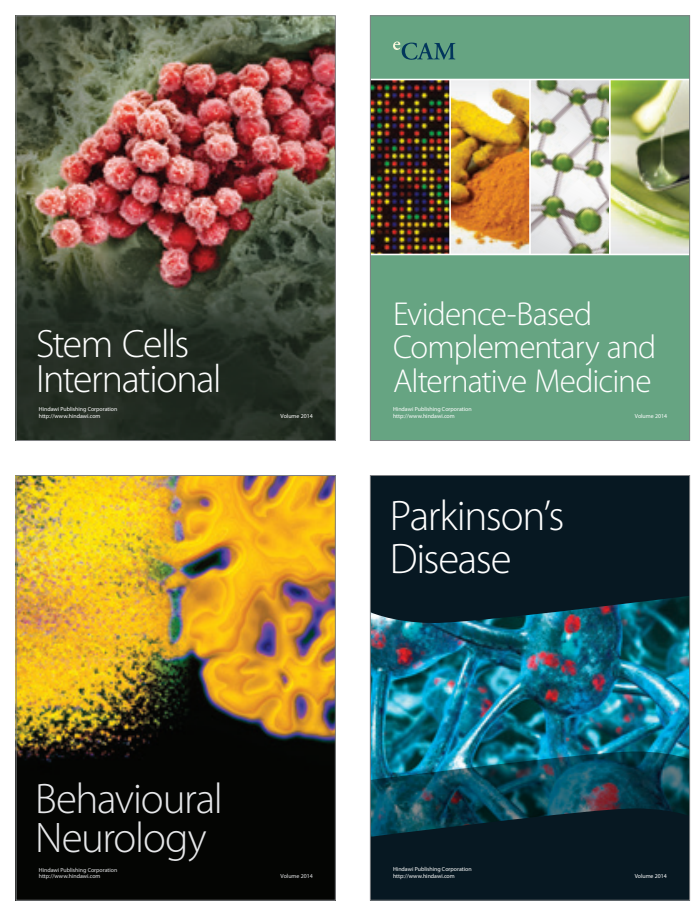

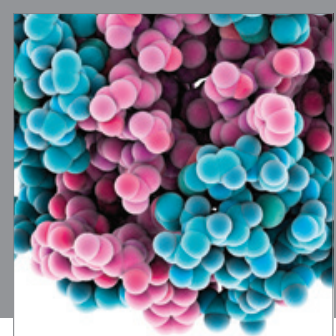

Journal of
Diabetes Research

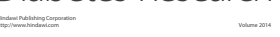

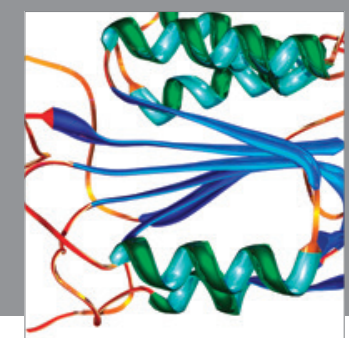

Disease Markers
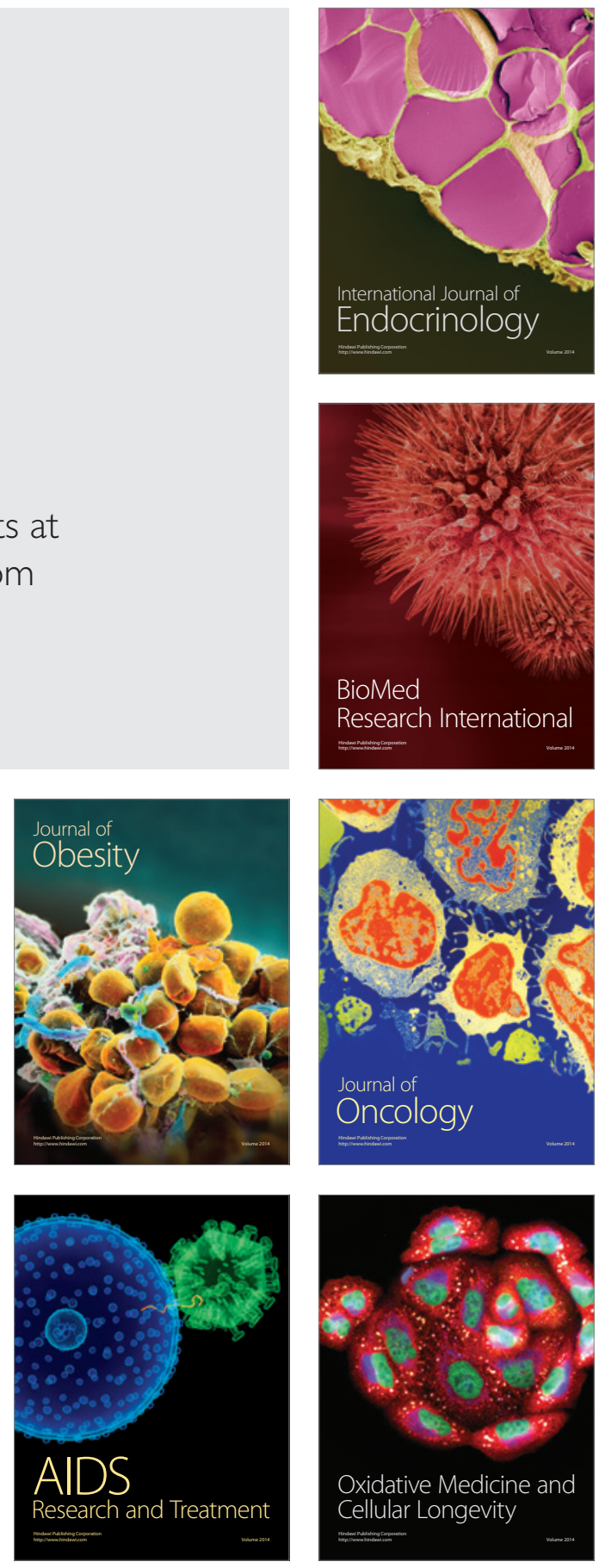